\title{
UNIVERSITYOF
}

FORWARD

THINKING

WESTMINSTER ${ }^{\text {用 }}$

WestminsterResearch

http://www.westminster.ac.uk/westminsterresearch

Characterisation of tabanid flies (Diptera: Tabanidae) in South

Africa and Zambia and detection of protozoan parasites they are harbouring

Taioe, M.O., Motloang, M.Y., Namangala, B., Chota, A., Molefe, N.I., Musinguzi, S.P, Suganuma, K., Hayes, P.M., Tsilo, T.J., Chainey, J., Inoue, N. and Thekisoe, O.M.M.

This journal article has been accepted for publication and will appear in a revised form, subsequent to peer review and/or editorial input by Cambridge University Press in Parasitology.

(C) Cambridge University Press, 2017

The final definitive version in the online edition of the journal article at Cambridge Journals Online is available at:

https://doi.org/10.1017/S0031182017000440

The WestminsterResearch online digital archive at the University of Westminster aims to make the research output of the University available to a wider audience. Copyright and Moral Rights remain with the authors and/or copyright owners.

Whilst further distribution of specific materials from within this archive is forbidden, you may freely distribute the URL of WestminsterResearch: ((http://westminsterresearch.wmin.ac.uk/)).

In case of abuse or copyright appearing without permission e-mail repository@westminster.ac.uk 


\section{Characterisation of tabanid flies (Diptera: Tabanidae) in South Africa and Zambia and detection of protozoan parasites they are harbouring}

RUNNING TITLE: Tabanids and haemoprotozoa

MOETI O. TAIOE ${ }^{1}$, MAKHOSAZANA Y. MOTLOANG $^{2}$, BONIFACE NAMANGALA ${ }^{3}$, AMOS CHOTA ${ }^{3}$, NTHATISI I. MOLEFE ${ }^{4}$, SIMON P. MUSINGUZI ${ }^{4}, \mathrm{KEISUKE}^{-}$ SUGANUMA ${ }^{4}$, POLLY HAYES ${ }^{6}$, TOI J. TSILO ${ }^{7}$, JOHN CHAINEY $^{8}$, NOBORU INOUE $^{5}$ and ORIEL M. M. THEKISOE ${ }^{1 *}$

${ }^{1}$ Unit for Environmental Sciences and Management, North West University, Potchefstroom Campus, Private Bag X6001, Potchefstroom, 2520, South Africa ${ }^{2}$ Parasites, Vectors and Vector-borne Diseases, ARC-Onderstepoort Veterinary Institute, Private Bag X05, Onderstepoort, 0110, South Africa

${ }^{3}$ Department of Paraclinical Studies, School of Veterinary Medicine, University of Zambia, Lusaka, Zambia

${ }^{4}$ National Research Center for Protozoan Diseases, Obihiro University of Agriculture and Veterinary Medicine, Obihiro, Hokkaido 080-8555, Japan

5 Obihiro University of Agriculture and Veterinary Medicine, Obihiro, Hokkaido 0808555, Japan

${ }^{6}$ Department of Biomedical Sciences, University of Westminster, London, United Kingdom

${ }^{7}$ Agricultural Research Council-Small Grain Institute, Bethlehem, 9700, Free State, South Africa

${ }^{8}$ Department of Entomology, The Natural History Museum, London, U.K.

${ }^{*}$ Corresponding author:

Prof. Oriel M.M. Thekisoe, Ph.D.

Unit for Environmental Sciences and Management, North West University - Potchefstroom Campus, Private Bag X6001, Potchefstroom, 2520, South Africa

E-mail: oriel.thekisoe@nwu.ac.za

Tel.: +27-18-299-2521, Fax: +27-18-299-2503 


\section{SUMMARY}

Tabanids are haematophagous flies feeding on livestock and wildlife. In the absence of information on the relationship of tabanid flies and protozoan parasites in South Africa and Zambia, the current study was aimed at characterizing tabanid flies collected in these two countries as well as detecting protozoan parasites they are harbouring. A total of 527 tabanid flies were collected whereby $70.2 \%$ were from South Africa and 29.8\% were from Zambia. Morphological analysis revealed a total of 5 different genera collected from the sampled areas namely: Ancala, Atylotus, Haematopota, Philoliche and Tabanus. DNA extracted from South African Tabanus par and T. taeniola tested positive for the presence of Trypanosoma congolense and T. theileri whilst one member from T. par was positive for T. brucei-like parasite. DNA extracted from Zambian tabanid flies tested positive for the presence of Besnoitia besnoiti at 1.27\% (2/157), Babesia bigemina 5.73\% (9/157), Theileria parva-like species 30.11\% (30/157) and 9.82\% (14/157) for Trypanosoma evansi-like species. This study is the first to report on Babesia and Theileria parasites in tabanid flies. Further investigations are required to determine the role of tabanids in transmission of the detected protozoan parasites in livestock and wildlife in South Africa and Zambia.

Key words: Horse flies, tabanids, Babesia bigemina, Besnoitia besnoiti, Theileria parva, Trypanosoma species. 
KEY FINDINGS

- A total of 10 tabanid fly species was collected and identified from animal trypanosomosis endemic area in South Africa.

- A total of 8 tabanid fly species was collected and identified from two animal trypanosomosis endemic areas in Zambia.

- Trypanosoma brucei-like species, T. congolense and T. theileri were detected by PCR from whole genomic DNA extracted from tabanid flies in South Africa.

- Trypanosoma evansi-like species, Babesia bigemina, Besnoitia besnoiti, Theileria parva parasites were detected by PCR from whole genomic DNA extracted from tabanid flies in Zambia.

- This is the first scientific report of detection of protozoan parasites in tabanid flies in South Africa and Zambia by PCR. 


\section{INTRODUCTION}

Tabanids are robust medium to large $(6-30 \mathrm{~mm})$ biting flies commonly referred to as horse or deer flies (Nevill et al. 1994; Service, 2012). They belong to the family Tabanidae which is further divided into four subfamilies, namely Chrysopsinae, Pangoniinae, Scepsidinae and Tabaninae, comprising of more than 4,400 species belonging to 114 genera, with a cosmopolitan distribution (Baldacchino et al. 2014a). However, in Africa only members from the subfamilies Chrysopsinae, Tabaninae, and various species of the genus Philoliche from the subfamily Pangoniinae, are of economic, medical and veterinary importance (Nevill et al. 1994). In southern Africa there are about 410 species with nine dominant genera (Nevill et al. 1994).

The mechanical transmission of various pathogens by tabanid flies has been known for decades (Zumpt, 1949). This mode of transmission may either occur through contamination of mouthparts or regurgitation (Foil and Gorham, 2000; Baldacchino et al. 2013a). Defecation is also significant as pathogens can be ingested and deposited on food or other surfaces, however if the pathogens do not multiply within the alimentary canal of the insect then this is defined as mechanical transmission (Foil and Gorham, 2000). Tabanid flies are vectors of most disease causing bacteria and viruses in animals and humans such as Bacillus anthracis, Listeria monocytogenes, Anaplasma marginale, Coxiella burnetii, and rinderpest virus (Chainey, 1993; Nevill et al. 1994; Esterhuizen, 2006; Baldacchino et al. 2014a; Hornok et al. 2014). Protozoan parasites, including the apicomplexan Besnoitia besnoiti and various trypanosome species (Trypanosoma brucei brucei, T. congolense, $T$. evansi, $T$. equiperdum, $T$. theileri and $T$. vivax), have also been reported to be amongst the haemoparasites disease agents transmitted by tabanid flies (Zumpt 1949; Nevill et al. 1994; Desquenes and Dia, 2003a,b, 2004; Ahmed et al. 2005; Sinshaw et al. 2006; Baldacchino et al. 2014a,b). These pathogens may either be biologically or mechanically transmitted to susceptible hosts during interrupted feeding by the flies. As a result tabanid flies cause major economic losses to both agriculture and dairy production sectors (Baldacchino et al. 2014a).

Most research on the prevalence of Trypanosoma, Besnoitia, Babesia and Theileria parasites has been conducted in South Africa and Zambia (Zumpt, 1949; Bigalke and Prozesky, 2004; Hunfeld et al. 2008; Yamada et al. 2009, Namazi et al. 2010; Mwandiringana et al. 2012; Sahinduran, 2012; Baldacchino et al. 2014a). However, most of these studies were focused on the affected vertebrate hosts or 
known vectors such as ticks or tsetse flies. There is a knowledge gap in the recent abundance of tabanid flies in South Africa and Zambia. Additionally, there is no data on the occurrence of protozoan parasites in tabanid flies from southern Africa. As a result, in the current study we report on characterisation of tabanid flies in South Africa and Zambia. Furthermore this study has conducted molecular detection of protozoan parasites harboured by tabanid flies. 


\section{MATERIALS AND METHODS}

Study sites

In South Africa tabanid flies were collected from three game reserves in north-eastern KwaZulu-Natal, namely, Charters Creek (28¹3'37"S; 032²4'1"E), Hluhluwe-Imfolozi

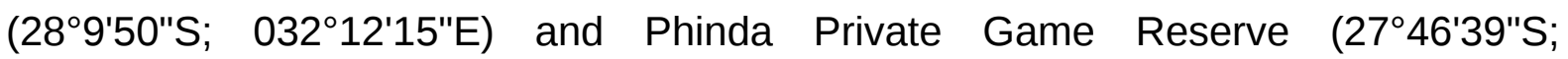
$\left.032^{\circ} 20^{\prime} 57^{\prime \prime E}\right)$. In Zambia tabanid flies were collected in South Luangwa National Park $\left(13^{\circ} 10^{\prime} 0.2^{\prime \prime} S, 031^{\circ} 29^{\prime} 59.8\right.$ 'E) in the Mambwe district of the Eastern Province and Kafue National Park (14²8'52.9'S, 026 13'17.7'E) in the Itezhi-tezhi district of Central Province (Fig. 1).

\section{Collection of tabanid flies}

A total of $18 \mathrm{H}$-traps (6 traps per game reserve placed at $100 \mathrm{~m}$ apart) were used to capture tabanid flies in three game reserves in South Africa in summer (November 2014). In Zambia sampling was done in summer (November 2015) with 11 Biconical traps (11 placed $200 \mathrm{~m}$ apart). All traps were kept at each sampling site for 5 days whilst the flies were harvested daily.

\section{Identification and characterization of tabanid flies}

Sequential photographs of different features of the flies were captured using a Nikon AZ 100 M multi zoom microscope (Nikon Inc., USA). Tabanid flies were then identified to species level by discerning unique characters that differentiated between species as described by Oldroyd (1954), Yagi (1964), Veer (1999) and Morita (2008). The distribution and occurrence of tabanids in South Africa was confirmed in accordance with Usher (1972).

\section{DNA extraction}

The whole fly was homogenised as described by Diallo et al. (1997), thereafter genomic DNA (gDNA) was extracted using the Zymo insect DNA extraction kit following the manufacturer's protocol (Zymo Research Corporation, USA) and stored at $-32^{\circ} \mathrm{C}$ until used.

\section{Amplification of tabanid flies DNA by PCR}

In order to supplement morphological identification of tabanid flies, PCR targeting the CO1 gene was conducted to identify tabanid fly DNA to species level and to further 
determine their phylogenetic position in comparison to other related taxa. The primers which amplified approximately $653 \mathrm{bp}$ fragment of $\mathrm{CO} 1$ gene are shown in Table 1. In a total volume of $25 \mu$ the PCR mixture contained $12.5 \mu$ AmpliTaq Gold $\otimes 360$ PCR Master Mix (AmpliTaq Gold® DNA Polymerase 0.05 units/ $\mu$, Gold buffer $[30 \mathrm{mM}$ Tris/ $\mathrm{HCl} \mathrm{pH} \mathrm{8.05,} 100 \mathrm{mM} \mathrm{KCl}$ ], $400 \mathrm{mM}$ of each dNTP and $5 \mathrm{mM} \mathrm{MgCl}$ ) (Applied Biosystems, California, USA), $2.5 \mathrm{mM}$ of each primer, $2 \mu$ of template DNA and double distilled water $\left(\mathrm{ddH}_{2} \mathrm{O}\right)$ was added to final volume. Genomic DNA of Glossina morsitans morsitans obtained from a colony of National Research Center for Protozoan Diseases, Obihiro University of Agriculture and Veterinary Medicine was used as a positive control and double distilled water $\left(\mathrm{ddH}_{2} \mathrm{O}\right)$ as a no DNA template negative control. PCR conditions were set as described by Sari et al. (2012).

\section{Detection of protozoan parasite DNA by PCR}

PCR with universal trypanosome primers (Table 1 ) targeting the internal transcribed spacer 1 (ITS1) gene was used to detect trypanosome DNA from the tabanid flies. The genomic DNAs of $T$. congolense (IL 3000); T. b. brucei (GUTat 3.1) and T. theileri (Japan Isolate) were used as positive controls. PCR conditions were set as described by Njiru et al. (2005).

The PCR described by Namazi et al. (2011) with primers (Table 1) amplifying $1065 \mathrm{bp}$ fragment of ITS1-5.8S-ITS2 rDNA gene was conducted for detection of Besnoitia besnoiti DNA from tabanid flies. The Besnoitia besnoiti donated by University of KwaZulu-Natal was used as positive control.

The PCR assay for amplification of piroplasma DNA (Babesia and Theileria species) was conducted with RLB primers (Table 1) targeting the $390-430 \mathrm{bp}$ fragment of the hypervariable region V4 of the 18S rRNA. The genomic DNA of Babesia bigemina (Argentina strain) and Theileria parva (Muguga isolate) were used as positive controls. The PCR was conducted according to protocol described by Ica et al., (2007).

For detection of Trypanosoma, piroplasmas and B. besnoiti the PCR mixture was prepared with AmpliTaq Gold $囚 360$ Master Mix (Applied Biosystems, USA) as described above. For all reactions the $\mathrm{dd}_{2} \mathrm{O}$ as a no DNA negative control. PCR product detection was done on a $1 \%$ gel electrophoresis stained with GelRed DNA stain (Biotium. Inc, USA) and visualised under UV light. 


\section{Sequencing and BLAST}

The PCR amplicons were purified using the QIAGEN Gel Purification Kit (QIAGEN, USA) according to manufactures protocol. Sequencing was conducted using BigDye ${ }^{\circledR}$ terminator cycle sequencing kit according to the manufacture's protocol (Applied Biosystems, California, USA). Thereafter, the eluent was loaded into a 96 well plate and placed in $\mathrm{ABI}$ Prism 3100 Genetic Analyzer, where sequencing electrophoresis occurred using a $36 \mathrm{~cm}$ capillary array and POP-7 ${ }^{\text {TM}}$ polymer (Applied Biosystems, California, USA). Analysis of the data was done using the Sequence Analyzer software version 1.7.1 (Developed by Will Gilbert, http://informagen.com/SA/). Retrieved gene sequences were edited using BioEdit (Hall, 1999). To confirm sequences obtained from all PCR analysis nucleotide basic local alignment search tool (BLASTn) was used (www.ncbi.nlm.nih.gov/blast/). The gene sequences with $80 \%$ to $100 \%$ similarity match score were considered as significant.

\section{Phylogenetic analysis}

The CO1 gene sequences were aligned by Clustal W using the multiple alignment fast fourier transform (MAFFT) program to conduct multiple and pair-wise sequence alignments (Katoh and Standley, 2013). Thereafter, the aligned sequences were trimmed using TrimAl version 1.4 to remove the uneven ends from the aligned sequences. The trimmed alignment was subsequently transferred to MEGA 6 for Maximum likelihood (ML) and Geneious (Ver. 7.1) bioinformatics software package for Bayesian inference $(\mathrm{BI})$ analyses. The alignment consisted of a total of 51 gene sequences (636 bp long) with 20 sequences resulting from the current study and 31 comparable sequences retrieved from NCBI GenBank. For ML analysis 100000 bootstrap replicates. The BI phylogeny was constructed using MrBayes Ver. 3.2.1 plugin on Geneious (Ver. 7.1) and the parameters were set as described by Morita et al. (2016).

\section{Statistical analysis}

The prevalence of each parasite species were presented in proportions and summarized tables according to independent variables such as tabanid fly species as 
well as the locality where the fly was collected. The Kruskal-Wallis $\chi^{2}$ analysis of variance by ranks at a significance level of $95 \%$ was used to determine the significance in the overall distribution of the tabanid flies in the sampled countries. Thereafter, fisher's exact test was used to determine the difference at $P<0.05$ for the prevalence of Besnoitia, Babesia, Theileria and Trypanosoma parasites between infected species and different localities.

\section{RESULTS}

Tabanid flies collected from South Africa and Zambia

A total of 527 tabanid flies were collected from the two sampled countries with 370 from South Africa (Table 2) and 157 from Zambia (Table 3). Morphological analysis revealed a total of 5 different genera collected from the sampled areas namely: Ancala, Atylotus, Haematopota, Philoliche and Tabanus with a total of 14 different species including 10 collected from South Africa and 8 were from Zambia.

Tabanid flies captured from South Africa were Ancala africana, Atylotus agrestis, A. fuscipes, A. nigromaculatus, Philoliche aethiopica, Tabanus gratus, T. taeniatus, T. laverani, T. par and T. taeniola (Table 2). The dominant species from the three sampled game reserves were Tabanus par (41.6\%) and T. taeniola (38.4\%), whilst Tabanus gratus (0.8\%) was the least. Charters Creek Game Reserve $(55.7 \%)$ had the highest species abundance followed by Hluhluwe-Imfolozi Game Reserve (29.4\%) and Phinda Private Game Reserve (14.9\%) with the least number of flies captured (Table 2). There was significant difference at $p=0.03$ (Kruskal-Wallis $X^{2}=$ 7,032 , df = 2) in the overall distribution of the tabanid fly population throughout the three sampled game reserves in KwaZulu-Natal Province, South Africa.

The tabanid fly species collected from Zambia were Atylotus agrestis, $A$. diurnus, Haematopota sp., Tabanus taeniatus, T. conformis, T. conspicuus, T. par and T. taeniola (Table 3). The most dominant species captured from the two provinces was Tabanus taeniatus (49.0\%) followed by T. taeniola (26.1\%) and the least was $T$. conspicuus (0.6\%). The majority of samples were collected from Mambwe district in the Eastern Province (94.3\%) and the Itezhi-tezhi district from the Central Province $(5.7 \%)$ had the smallest sample size (Table 3). There was significant difference at $p=$ 0.01 (Kruskal-Wallis $X^{2}=6.893$, df $=1$ ) in the overall distribution of the tabanid fly population throughout the two sampled provinces in Zambia. 


\section{Morphological identification of tabanid flies}

We identified several tabanid flies species based on their morphological characteristics and provided reference to the author whom described the fly as follows:

\section{Ancala africana Gray, 1922}

This species was only collected from South Africa. It was identified according to the characteristics described by Oldroyd (1954) and Yagi (1964). Accordingly, the specimen had an average body length of $17 \mathrm{~mm}$. The eyes were greenish with no bands in living specimens and black on dried specimens (Fig. 2A1). The callus was dark brown and had a quadrate shape with a trace of a median extension (Fig. 2A1 (i)). The facial area was yellow covered with golden hairs. The antennae were blackish in pigmentation. It had an orange yellowish thorax with no patterns (Fig. 2A2). The dorsum of abdomen was orange with black hair patches on the margins of all tergites ventrally and the last segment was completely black (Fig. 2A3 (ii)). The wing membrane had broad transverse brown band shading crossing the distal cell but not reaching the hind margin and extends to the tips of the wing veins R2+3 and R4 (Fig. 2A4).

Atylotus agrestis Wiedemann, 1828

This species was collected from both South Africa and Zambia. It was identified by characteristics described by Oldroyd (1954), Yagi (1964) and Veer (1999). The specimen had an average body length of $14 \mathrm{~mm}$. The eyes were rusty brown with a trace of a single purple band in dried specimen and reddish black in living specimen (Fig. 2B1). The frons was grey and yellow towards the vertex. The proboscis and first segment of the antennae were light orange in colour and the rest of the antennae were bright yellow (Fig. 2B1 (ii)). The upper and lower calli were circular and shining brown in colour (Fig. 2B1 (i)). Face and parafacials were white with long white hairs (Fig. 2B1). The thorax was black with slight traces of four brown longitudinal sublateral stripes. The scutellum was uniformly brownish in colour (Fig. 2B2 (ii)). The abdomen was black with two orange sub lateral stripes and yellow ground colour (Fig. 2B2). The 
veins and costa of the wings were pale yellow and only the stigma was slightly brownish (Fig. 2B4 (iv)).

\section{Atylotus diurnus Walker, 1850}

This species was only collected from Zambia. It was identified by characteristics described by Oldroyd (1954). The specimen had an average body length of $15 \mathrm{~mm}$. The eyes were reddish black with no traces of bands on both living and dried specimens (Fig. 2C1). The frons had yellow-grey fine hairs and a fairly large yellowish triangle at the vertex (Fig. 2C1 (i)). Calli were dark brown with the upper callus was slightly elongated and the subcallus flat (Fig. 2C1 (ii)). The face and parafacials had yellowish grey tomentum. The antennae were yellowish orange from the scape and more light yellow towards the tips (Fig. 2C1 (iii)). The proboscis was dark-brown and stalky. The thorax had a black mesonotum with no patterns and covered with thin ashy-grey hairs. The dorsum of the abdomen was ashy-grey with clear patterns made up of black and golden hairs with three longitudinal stripes (Fig. 2C3). The wings were clear with a bit of yellow colouration towards the ends and the stigma (Fig. 2C4 (iv)).

\section{Atylotus fuscipes Ricardo, 1908}

This species was only collected from South Africa. It was identified by characteristics described by Oldroyd (1954), Yagi (1964) and Veer (1999). The average body length of this specimen was $14 \mathrm{~mm}$. Eyes of the dried specimen were reddish brown on living and dried specimens (Fig. 2D1). The frons was yellowish grey with a yellow triangular shape at the vertex and a distinct median ocellus (Fig. 2D1 (i)). The calli were black, ovate to quadrate in shape. The proboscis was brownish. The antennae were pale yellowish at the first segment with black hairs and more orange at the terminal (Fig. 2D1 (ii)). The thorax was ashy grey with a narrow dark brown median stripe and mere traces of sublateral stripes. The abdomen was dorsum black with two orange sublateral stripes that end on the fifth tergite. The orange stripes were more broad at the first two segments (Fig. 2D2 (iii)) and had golden hairs. The wings were clear with brownish veins (Fig. 2D4 (iv)).

Atylotus nigromaculatus Ricardo, 1900 
This species was only collected from South Africa. It was identified by characteristics described by Oldroyd (1954). The specimen had an average body length of $13 \mathrm{~mm}$. The eyes were reddish brown on living specimen and yellowish with a trace single purple band on dried specimen on dried specimen. The frons was slightly converted with yellowish grey hairs and large black V-shaped calli at the vertex (Fig. 2E1 (i)). Hairs around the head were mainly yellow and mixed with some few black ones. The face and parafacials had white fine hairs. The palpi were white and swollen at the base (Fig. 2E1 (ii)). The proboscis was black-brown in colour. The thorax was black with a thin ashy grey-brown tomentum and fairly distinct narrow yellowish grey longitudinal stripes. The scutellum was ashy grey-brown (Fig. 2E2 (iii)). The abdomen dorsally, was black-brown with a little reddish colour on the sides of the first two segments with three prominent yellowish grey longitudinal parallel sided stripes (Fig. 2E2). The wings were clear with pale yellow stigma and yellowish veins that darken towards the margins (Fig. 2E4)

\section{Philoliche aethiopica Thunbrg, 1789}

This species was only collected from South Africa. The specimen was identified by characteristics described by Morita (2008). The average body length of the specimen was $14 \mathrm{~mm}$. The head was black with black eyes (Fig. 2F1). The frons was strongly divergent towards antennae and mahogany brown in colour (Fig. 2F1 (i)). The first two segments of the antennae were brown with black hairs. The proboscis was black and equal to the body length (Figure. 2F1 (ii)). The inner eye margins had an obtuse angle (Fig. 2F1 (iii)). The thorax was dark brown with no sublateral stripes. The abdomen was bright reddish orange with small blue-black medial spots on the first four tergites dorsally and ventrally (Fig. 2F2 and Fig. 2F3). The wings were slightly smoky and darkened slightly at cross-veins (Fig. 2F4).

\section{Tabanus taeniatus Macquart, 1834}

This species was collected from both South Africa and Zambia. The specimen was identified by characteristics described by Oldroyd (1954). The average body length of this specimen was $12 \mathrm{~mm}$. The eyes were green violet without bands on living specimens but appeared brownish black on dried specimens (Fig. 2G1). The frons was honey-brown with black hairs and yellow hairs towards the margins of the eyes. 
The upper and lower calli were irregular and black in colour (Fig. 2G1 (i)). The proboscis was blackish with orange yellowish palpi. The thorax had ashy black hairs and a faint narrow brown median line (Fig. 2G1 (ii)). The scutellum was blackish brown with patches of grey on the sides (Fig. 2G2 (iii)). The dorsum of the abdomen was ashy black with three whitish grey longitudinal stripes. The two sublateral stripes ended on the seventh tergite which was completely greyish. The hairs were black on the dark areas of the abdomen and whitish yellow on the grey stripes. The wings were clear with pale yellow veins and stigma (Fig. 2G4).

Tabanus gratus Loew, 1858

This species was only collected from South Africa. The specimen was identified by characteristics described by Oldroyd (1954). The average body length of this specimen was $12 \mathrm{~mm}$. The eyes were green with three crimson bands in both living and dry specimens (Fig. 2H1). The tomentum of the frons was yellowish grey and whitish towards the vertex. The calli were separated whereby, the lower callus was slightly square in shape and upper callus was oval and both were honey brown in colour (Fig. $2 \mathrm{H} 1$ (i)). The first two segments of the antennae were whitish and the rest orange. The face and parafacials were white with whitish hairs. The proboscis was brown (Fig. 2H1). The thorax had dark brown fine hairs with white median and sublateral stripes. The dorsum of the abdomen was dark brown with three clearly defined white stripes (Fig. 2H2). The median stripe was narrow on the second segment, becoming broadest on the hind margin of the forth segment and narrowing again towards the posterior (Fig. $2 \mathrm{H} 2$ (ii)). The wings were clear with yellow veins and an almost invisible stigma (Fig. 2H4).

\section{Tabanus laverani Surcouf, 1907}

This species was only collected from South Africa. The specimen was identified by characteristics described by Oldroyd (1954). The average body length of this specimen was $14 \mathrm{~mm}$. The eyes were black greenish on dried specimen and banded in living specimen (Fig. 2I1). The tomentum of the frons was light grey with black patches on the vertex and the upper callus. The palpi were covered with white hairs and the proboscis was dark brown. The first two segments of the antennae were reddish and the rest were bright orange with black hairs. The thorax had a bark brown thin hairs with a pair of faint light grey sublateral stripes which continued across the 
sides of the scutellum (Fig. 211 (i)). The knobs of the halters were whitish yellow (Fig. $2 \mathrm{I} 2$ (ii)). The dorsum of the abdomen was light brown on the first two tergites and the rest was dark brown with a bold parallel sided whitish median stripe (Fig. 2I2). The lateral margins were greyish with no patterns (Fig. 2 I2 (iii)). The wings were clear with a dark brown stigma (Fig. 214 (iv)).

\section{Tabanus par Walker, 1858}

This species was collected from both South Africa and Zambia. The specimen was identified by characteristics described by Oldroyd (1954). The average body length of this specimen was $12 \mathrm{~mm}$. The eyes were emerald green and without bands on both living and dry specimens (Fig. 2J1). The tomentum of the frons was golden yellow with black hairs. The calli was yellowish brown and broadly united into an elongated, onion shape figure (Fig. $2 \mathrm{~J} 1$ (i)). The subcallus, face and parafacials were lemon yellow with yellow hairs. The palpi were yellow with black and pale yellow hairs. The proboscis was yellow orange in colour (Fig. 2J1). The first two segments of the antennae were yellow with yellow hairs and the rest were bright orange (Fig. $2 \mathrm{J1}$ (ii)). The thorax was without any patterns and scutellum was black in ground colour. The dorsum of the abdomen was orange without any patterns and clothed with a mixture of black and golden yellow fine hairs (Fig. 2J2). The wings were clear with yellow veins and stigma (Fig. 2J4).

Tabanus taeniola Palisto de Beavios, 1807

This species was collected from both South Africa and Zambia. The specimen was identified on characteristics described by Oldroyd (1954). The average body length of this specimen was $16 \mathrm{~mm}$. The eyes were reddish brown on dried specimen and dull copper green in living specimens with short and sparse pubescence (Fig. 2K1). The facets were equal in size with no visible bands. The frons was reddish brown with a thin tomentum covered mostly by white hairs. The calli was reddish brown (Figure. $7 \mathrm{~K} 1$ (i)) and the proboscis was black (Fig. 2K1). The first segment of the the antenna was whitish grey, the second a bit reddish with black hairs and the rest were blackish (Fig. 2K1 (ii)). The thorax was black and the tomentum reddish brown on the sides. The scutellum was dull reddish with grey tomentum on the sides and grey medially. The abdomen was dorsally reddish brown at the first four tergites and the fifth to 
seventh tergites are dark brown (Fig. 2K2). On the abdomen there were three conspicuous longitudinal whitish stripes (Fig. 2K2). The median stripes were triangular and appeared to be fused (Fig. 2K2 (iii)). The wings were clear with a pale stigma (Fig. 2K4).

Haematopota longa Ricardo, 1906

This species was only collected in Zambia. The specimen was identified by characteristics described by Oldroyd (1952). The average body length of this specimen was $10 \mathrm{~mm}$. Eyes on living and dry specimens were reddish black (Fig. 2L1). The frons was square, pale yellow and slightly grey on the sides. The specimen had circular black paired spots and not touching the eye margins (Fig. 2L1 (i)). The callus was transverse, low, without median extensions and black in colour (Fig. 2L1 (ii)). The first segment of the antennae were cylindrical and elongated and as long as the frons and without subapical notches (Fig. 2L1 (iii)). The rest of the antennae were reddish brown and the last segment was black. The face and parafacials were whitish grey. The thorax was light brown in colour with greyish brown distinct patterns at the end of sublateral stripes and a median grey stripe (Fig. 2L1 (iv)). The dorsum of the abdomen was dark brown with pale side margins. The wings were light brown with dark brown to black rosettes covering the whole wing (Fig. 2L4 (v)).

\section{Tabanus conformis Walker, 1848}

This species was only collected from Zambia. The specimen was identified by characteristics described by Oldroyd (1954). This specimen was fairly large with an average length of $12 \mathrm{~mm}$. The eyes were dark purplish with no bands on both living and dry specimens (Fig. 2M 1). Tomentum of the frons was dark brown in the middle and greyish towards the vertex and lower callus (Fig. 2M1 (i)). Sub-callus and parafacials were light brown and the proboscis was black-brown (Fig. 2M1 (ii)). The thorax had brown fine hairs and an ashy-grey pigment towards the edges with faint greyish sublateral stripes (Fig. 2M2). The dorsum of the abdomen was orange with short black hairs which give it a brown colour to the naked eye (Fig. 2M2 (iii)). There was a grey-yellowish median stripe that is clearly prominent covered with yellow hairs (Fig. 2M3). The wings were smoky grey becoming more brownish towards the margins (Fig. 2M4).

Tabanus conspicuus Ricardo, 1908 
This species was only collected from Zambia. The specimen was identified by characteristics described by Oldroyd (1954). The body of this specimen was large with $19 \mathrm{~mm}$ in average length. The eyes were dark reddish brown with no bands on both living and dry specimens (Fig. 2N1). The tomentum of the frons was yellowish grey to reddish brown (Fig. 2N1 (i)) and the proboscis was black-brown. The thorax had yellow fine hairs with a brown tomentum between lateral stripes (Fig. 2N1 (ii)). The scutellum was yellow-brown with a red tip (Fig. 2N (iii)). The dorsum of the abdomen was predominantly yellow with a very broad median stripe with triangles united into a notched stripe and brown in colour giving the appearance of a yellow abdomen with two narrow brown stripes (Fig. 2N2). The wings were slightly smoky with distinct colourings along the veins (Fig. 2N4).

\section{Phylogeny of southern African tabanid flies}

Sequences used for both $\mathrm{ML}$ and $\mathrm{BI}$ phylogenetic analyses were from members of the genera Atylotus, Hybomitra, Tabanus, Haematopota and Philoliche as well as Chrysops representing three tribes from the family Tabanidae. Symphoromyia [JN582255] from the family Rhagionidae was used as an out-group (Fig. 3a and b). All tabanid CO1 sequences generated from this study clustered with corresponding congener. In both tree topologies monophyly within the family Tabanidae is well supported. The ML (Fig. 3a) revealed 7 major clades (I - VII) with strong bootstrap support values, namely, Clade I - Tabanus 1 spp.; Clade II - Hybomitra spp.; Clade III - Tabanus 2 spp.; Clade IV - Haematopota spp.; Clade V - Atylotus spp.; Clade VI Chrysops spp. and Clade VII - Philoliche spp. ). The BI analysis (Fig. 3b) also produced 7 clades namely, Clade I - Philoliche spp.; Clade II - Chrysops spp.; Clade III - Atylotus spp.; Clade IV - Haematopota spp.; Clade V - Tabanus 2 spp.; Clade VI Hybomitra spp. and Clade VII -- Tabanus 1 spp. respectively. In both tree topologies, sequences generated in this study are in bold font.

\section{Occurrence of protozoan parasites from South African tabanid flies}

From the 370 South African tabanid flies analysed, none tested positive for the presence of Besnoitia, Babesia and Theileria DNA by PCR. Only 8.38\% (31/370) of Trypanosoma DNA was detected from South African tabanid flies (Table 4). 
Only flies collected from Hluhluwe-Imfolozi 14.7\% (16/109) and Charters Creek 7.3\% (15/206) game reserves were positive for the presence of trypanosome DNA and none were positive from Phinda Private Game Reserve (Table 4). Only members from Tabanus taeniola 11.97\% (17/142) and T. par 9.09\% (14/154) were positive. The T. congolense (Savannah) was detected in T. par 3.25\% (5/154) and T. taeniola 7.04\% (10/142), whilst T. theileri was detected in T. par 5.19\% (8/154) and T. taeniola 4.61\% (7/142). Trypanosoma brucei-like DNA, was detected from only 0.65\% (1/154) T. par specimen from Charters Creek Game Reserve (Table 4). There was no significant difference at $P=0.1131$ (one tailed Fisher's Exact Test (FET)) in the prevalence of $T$. congolense (Savannah) as well as at $P=0.5650$ (one tailed FET) for $T$. theileri between Tabanus par and T. taeniola from South Africa.

Nucleotide BLAST analysis confirmed the T. congolense (Savannah) positive samples from T. par had $89 \%$ to $90 \%$ identity match with T. congolense LS25 isolate [JX910374] from the NCBI GenBank, whilst those from T. taeniola had 90\% to 97\% identity match score with T. congolense isolate TS07210 [JN673389]. The T. theileri parasite detected from T. par and T. taeniola had $80 \%$ to $90 \%$ identity match score with T. theileri [ZPU2807] and [JN673396] isolates. The T. brucei-like species gene sequence obtained from T. par matched with T. brucei Suzena strain [AF306775] and with T. evansi isolate 006 [HQ593640] by 93\% identity match score (shown in the supplementary image S. 1). Additionally, neither T. vivax nor mixed infections were detected from the analysed samples.

\section{Prevalence of protozoan parasites from Zambian tabanid flies}

From 157 tabanid flies that were collected from Zambia, a total of 35.03\% (55/157) tested positive for presence of $B$. besnoiti 1.27\% (2/157), Babesia spp. or Theileria spp. 24.84\% (39/157) and Trypanosoma evansi species $9.82 \% 1$ (4/157) by PCR. Only 1 sample of Tabanus conspicuus collected from Central Province was positive for Babesia bigemina and the remaining samples from Central Province were negative for the tested parasites. Eastern Province had the highest prevalence of the tested parasites with $34.62 \%$ (54/156) from the sampled flies.

The $B$. besnoiti DNA was detected only from Tabanus conformis (2/4) flies which were collected from the Eastern Province (Table 4). Due to the low number of positively tested tabanid flies by PCR no statistical analysis was conducted for the 
prevalence of $B$. besnoiti. The $B$. besnoiti PCR positive samples were sequenced and the BLASTn analysis showed that these gene sequences of the two species matched with B. besnoiti from Israel [DQ227420] with 87\% identity match score.

Amplification of the hypervariable region V4 of the 18S rRNA for either Babesia or Theileria parasites using species specific primers RLB-F2 and RLB-R2 showed that 24.84\% (39/157) of tested flies were positive for the presence of Babesia bigemina with 21.66\% (34/157) and Theileria parva-like with 3.18\% (5/157) (Table 4). All positive samples were from Eastern Province whereby Atylotus agrestis was the most infected at $62.50 \%(10 / 16)$ followed by $A$. diurnus at $100 \%(7 / 7)$ and $T$. taeniola at $17.07 \%$ (7/41). The $T$. taeniatus and $T$. conspicuus were the least infected with $3.90 \%(3 / 77)$ and $100 \%(1 / 1)$ respectively. There was no significant difference at at $P=1.0994$ (one tailed FET) in the prevalence of $B$. bigemina in all positively tested tabanid samples. The BLASTn analysis showed that the $B$. bigemina sequences obtained in this study matched with B. bigemina isolate MT26 [KU206297] with 90\% - 98\% identity match score (shown in the supplementary image S. 2).

Only samples from Tabanus taeniola tested positive for the presence of Theileria parasite at $3.18 \%$ (5/157). Due to the fact that only $T$. taeniola specimens tested positive for the presence of Theileria parasites, no statistical analysis was conducted to test the significance of Theileria parasites in positively tested samples. Analysis from BLASTn confirmed that sequences obtained from this study matches with T. parva isolate KNP102 [HQ684067] and T. parva [KM211712] by 83\% to 86\% identity match scores (shown in the supplementary image S. 3).

A total of $9.82 \%$ (14/157) tabanid flies from Zambia tested positive presence of Trypanosoma DNA (Table 4). The trypanosome infections were only detected from samples collected from Eastern Province and detection was from T. taeniola 17.07\% (7/41) and T. par $87.50 \%$ (7/8). There was a significant difference at $P=0.0007$ (one tailed FET) in the prevalence of Trypanosoma species in all positively tested tabanid samples. The BLASTn results showed that all recovered sequences in this study matched with Trypanosoma evansi isolate 006 [HQ593640] by $89 \%$ to $99 \%$ identity match score (shown in the supplementary image S. 4). A total of $75 \%(6 / 7) T$. par specimens from Zambia had mixed infections for B. bigemina and $T$. evansi as summarised in Table 4. Additional PCRs using OIE standard PCR primers described by Masinga et al. (1992) were conducted. Whereby only TBR primers for the detection of Trypanozoon spp. and TCS for the detection of $T$. congolense Savannah were 
tested positive for the analysed samples (S. 5, S. 6). None of T. congolense Kilifi and T. congolense Forest primers tested positive in samples from both samples countries.

\section{DISCUSSION}

Horse flies belonging to 5 different genera representing 14 species were recorded in the current study namely: Ancala, Atylotus, Haematopota, Philoliche and Tabanus. The overall number of members from the genus Tabanus was greater than all other genera combined.

The species of Chrysops and Hybomitra, as well as species from the subfamily Scepsidinae were not encountered from the two sampled countries. In a study of seasonal abundance of horse flies conducted for a period of 4 years in north eastern KwaZulu-Natal province by Esterhuizen (2006), no members from Scepsidinae were recorded. The last record of Scepsidinae members in southern Africa were reported by Usher (1972). Furthermore, Esterhuizen (2006) recorded only two species from the genus Chrysops from four years of sampling, this is an indication that species from the genus Chrysops are uncommon in sampled regions. Likewise, in studies conducted by Okiwelu (1975; 1976) on tabanids from Zambia in the miombo woodlands, Chrysops species were not reported.

Most studies conducted on the seasonal abundance of tabanid flies concluded that high numbers of flies are observed during the summer months or rainy seasons (Barros, 2001; Ahmed et al. 2005; Esterhuizen, 2006; Itina et al. 2013; Baldacchino et al. 2014a). The small Zambian sample size in the current study may be due to El Niño phenomenon (2015 - 2016) during the sampling period as it has resulted in unusually dry summer season which were extremely hot. Hence we also collected the fly samples in summer months in the current study.

Phylogeny of southern African tabanid flies observed in the current study supports monophyly in Tabanidae. Similar observation was reported previously where morphological analysis derived from genitalia and external characters as well as molecular techniques targeting mitochondrial (CO1) and nuclear (28S) genes also supported monophyly in Tabanidae (Lessard and Yeates, 2012; Lessard et al. 2013; Morita et al. 2016). However, the genus Tabanus was non-monophyletic as there was 
a split between Tabanus species from different ecozones. The Tabanus species from the current study are from the Afrotropic region and are genetically distinct from those found in the Nearctic and the Neotropical regions (Morita et al. 2016). Additionally, as observed in Fig. 3a (Clade D), the tribe Tabanini which is composed of members from the genera Atylotus, Hybomitra and Tabanus formed a parphyletic clade with each other. Findings in this study support observations by Morita et al. (2016) whereby, members from the subfamily Chrysopsinae appeared to be paraphyletic as shown in clade II of Fig. 3a and clade V of Fig. 3b. The tribe Haematopotini is monophyletic in both $\mathrm{ML}$ and $\mathrm{BI}$ analyses and these correspond to finding by Morita and colleagues (2016). However, Atylotus agrestis [KM111665] and Tabanus nigrovittatus [KT381971] branched on their own. In most phylogenetic analyses of tabanid flies and other closely related species there are normally uncertainties with the position of most species due to weak support observed from internal relationships (Yeates et al. 2007; Morita et al. 2016). Analyses generated in this study show that southern African tabanid flies do form well supported clades with corresponding congener however, they somehow appear to be genetically distinct from other related species.

It is well known that tabanids are vectors of most livestock pathogens causing diseases such as anaplasmosis, anthrax, animal trypanosomiasis, bovine viral leukosis, equine infectious anaemia virus and filarial worms, tularaemia, hog cholera as well as vesicular stomatitis (Zumpt, 1949; Foil and Hogsette, 1994; Esterhuizen, 2006; Service, 2012; Baldacchino et al. 2014a). In the current study DNA of four different protozoan parasites were detected by PCR, namely, Babesia bigemina, Besnoitia besnoiti, Theileria parva, Trypanosoma brucei-like, T. congolense, T. evansi-like and T. theileri.

Published literature has widely reported that horse flies (tabanids) and Stomoxys flies do transmit various species of trypanosomes and $B$. besnoiti (Desquesnes and Dia, 2003a; Desquesnes and Dia, 2003b; Bigalke and Prozesky, 2004; Desquesnes and Dia, 2004; Baldacchino et al. 2013a; Baldacchino et al. 2014a; Hornok et al. 2015). Occurrences of animal trypanosomes and tsetse flies are well reported in both South Africa and Zambia (Van den Bossche, 2001; Mamabolo et al. 2009; Gillingwater et al. 2010; Mwandiringana et al. 2012; Motloang et al. 2014; Nguyen et al. 2015; Dennis et al. 2014; Laohasinnarong et al. 2015; Mbewe et al. 2015; Renda et al. 2016). This is the first report of trypanosome occurrence from tabanid flies in South Africa and Zambia. Studies by Desquesnes and Dia (2003a; 
2003b; 2004) have demonstrated that mechanical transmission of $T$. vivax and $T$. congolense by $A$. agrestis and $A$. fuscipes. On the oher hand $T$. evansi is well known to be mechanically transmitted by biting flies including Stomoxys and tabanid flies (Sumba et al. 1998; Gutierrez et al. 2010; Desquesnes et al. 2013). It has been reported that trypanosomes can also develop within the midgut and hindgut of tabanid flies (Krinsky and Pechuman, 1975; Bose and Heister, 1993). We refer to T. bruceilike and $T$. evansi-like trypanosomes as these species have not been reported to occur in these countries and require further confirmation.

In the current study, $B$. besnoiti DNA has been detected in $T$. conformis collected in Zambia only. This is the first report of the occurrence of $B$. besnoiti in Zambia and the finding indicates possible circulation of the parasite in wildlife in Zambia. Bovine besnoitiosis has been reported to cause major economic losses in Angola, Cameroon, Botswana, Kenya, Namibia, South Africa, Sudan, Swaziland, Zaire and Zimbabwe (Bigalke and Prozesky, 2004). In South Africa cases of the disease have been documented from the Free State, KwaZulu-Natal, Limpopo, Mpumalanga, North-West and Western Cape Province respectively (Bigalke and Prozesky, 2004).

The current study has detected B. bigemina and T. parva DNA from tabanid flies collected from Zambia only. The occurrence of these tick-borne parasites in livestock and wildlife is well documented in both countries (OIE, 2008; Thompson et al. 2008; Yamada et al. 2009, Yusufmia et al. 2010; Pienaar et al. 2011; Simuunza et al. 2011; Terkawi et al. 2011; Mtshali et al. 2014). We report for the first time the occurrence of Babesia bigemina and Theileria parva in tabanid flies in Zambia.

Mechanical transmission of parasites by tabanid flies depends on numerous variables. Firstly, there has to be a high level parasitaemia in the host blood stream in order to contaminate the tabanid fly when taking a blood meal. Secondly, there must be a high density of potential mechanical vectors and close contact between the host animals and the vector flies (Desquesnes et al. 2009). Thirdly, the biology of the flies is another contributing factor, for instance, the size of the fly mouthparts, whereby larger mouthparts of flies mechanically transmit more parasites (Sumba et al. 1998; Baldacchino et al. 2013). Lastly, the duration of parasite survival on the mouthparts is shorter (24 hours) as compared to inside the crop and the gut (5 to 7 days) and this would allow delayed transmission as the flies can regurgitate infected blood into the host (Baldacchino et al. 2013). 


\section{CONCLUSION}

Baldacchino et al. (2014), states that tabanids are neglected subjects of research but important vectors of disease agents. In the current study 14 different tabanid species were collected from South Africa and Zambia. This is the first report of Besnoitia besnoiti, Babesia bigemina, Theileria parva and various trypanosome species from tabanid flies by PCR detection. Further studies on possible transmission of these parasites by tabanid flies in South Africa and Zambia are required as well as sampling the flies in livestock farming areas as only wildlife nature reserves were sampled in the current study. The presence of Trypanosoma brucei-like and T. evansi-like DNA from South Africa and Zambia respectively needs further confirmation. Control of vectors such as ticks and tsetse flies reduces the prevalence of tick-borne diseases and trypanosomosis respectively, but these diseases will not be eliminated if tabanid flies are not given the attention they deserve.

\section{ACKNOWLEDGEMENTS}

We thank the Ezemvelo KZN Wildlife for their cooperation. We are grateful to $\mathrm{Mr}$ Jerome Ntshangase (ARC-OVI Tsetse station) and Mr Timmy Baloyi (ARC- Small Grain Institute) for their technical assistance. Ms Joanita Viviers and Jani Reeder (NWU Amphibian Group) for taking tabanid fly specimen photos.

\section{FINANCIAL SUPPORT}

The first author is supported by DST-NRF Scarce Skills Scholarship Grant UID: 95090. This study was made possible by the National Research Foundation (NRF) Development Grant for Y-rated Researchers (OMMT, Grant number 93399). 


\section{REFERENCES}

Ahmed, A. B., Okiwelu, S. N. and Samdi, S. M. (2005). Species diversity and seasonal occurrence of some biting flies in southern Kaduna, Nigeria. African Journal of Biomedical Research. 8: 113-118.

Baldacchino, F., Muenworn, V., Desquesnes, M., Desoil, F., Charoenviriyaphap, T. and Duvallet, G. (2013). Transmission of pathogens by Stomoxys flies (Diptera: Muscidae): a review. Parasites. 20: 26. doi:10.1051/parasite/2013026.

Baldacchino, F., Desquesnes, M., Mihok, S., Foil, L. D., Duvallet, G. and Jittapalapong, S. (2014a). Tabanids: Neglected subjects of research, but important vectors of diseases. Infection, Genetic and Evolution. 28: 596-615. doi:10.1016/j.meegid.2014.03.029.

Baldacchino, F., Gard $\mid$ s, L., de Stordeur, E., Jay-Robert, P. and Garros, G. (2014b). Blood-feeding patterns of horse flies in the French Pyrenees. Veterinary Parasitology. 199: 283-288. doi:10.1016/j.vetpar.2013.10.009.

Barros, A. T. M. (2001). Seasonality and relative abundance of Tabanidae (Diptera) captured on horses in the Pantanal, Brazil. Memórias do Instituto Oswaldo Cruz, Rio de Janeiro. 96(7): 917-923.

Bigalke, R., D. and Prozesky, L. (2004). Besnoitiosis. In Infectious diseases of livestock (ed. Coetzer, J. A. W. and Tuskin, R. C.), pp. 351-359. Volume 1, $4^{\text {th }}$ ed. Oxford University Press, Cape Town, Southern Africa.

Bose, R. and Heister, N. C. (1993). Development of Trypanosoma (M.) theileri in tabanids. Journal of Eukaryote Microbiology. 40: 788-792.

Chainey, J. E. (1993). Insecta: Diptera, Tabanidae. Freshwater Invertebrates of the Malaysian Region. 786-790. 
De Beer, C., Venter, G. J.,Kappmeier Green, K., Esterhuizen, J., de Klerk, D. G., Ntshangase, J., Marc J.B. Vreysen, M. J. B., Pienaar, R., Motloang, M. Y., Ntantiso, L. and Latif, A. A. (2016). An update of the tsetse fly (Diptera: Glossinidae) distribution and African animal trypanosomosis prevalence in north-eastern KwaZuluNatal, South Africa. Onderstepoort Journal of Veterinary Research. 83(1): a1172. http://dx.doi.org/10.4102/ojvr.v83i1.1172.

Dennis, J. W., Durkin, S. M., Horsley Downie, J. E., Hamill, L. C., Anderson, N. E. and MacLeod, E. T. (2014). Sodalis glossinidius prevalence and trypanosome presence in tsetse from Luambe National Park, Zambia. Parasites and Vectors. 7: 378. http://www.parasitesandvectors.com/content/7/1/378.

Desquesnes, M. and Dia, M. L. (2003a). Trypanosoma vivax: mechanical transmission in cattle by one of the most common African tabanids, Atylotus agrestis. Experimental Parasitology. 103: 35-43. doi:10.1016/S0014-4894(03)00067-5.

Desquesnes, M. and Dia, M. L. (2003b). Mechanical transmission of Trypanosoma congolense in cattle by the African tabanid Atylotus agrestis. Experimental Parasitology. 105: 226-231. dio:10.1016/j.exppara.2003.12.014.

Desquesnes, M. and Dia M. L. (2004). Mechanical transmission of Trypanosoma vivax in cattle by the African tabanid Atylotus fuscipes. Veterinary Parasitology. 119: 9-19. doi:10.1016/j.vetpar.2003.10.015.

Desquenes, M., Biteau-Coroller, F., Bouyer, J., Dia M. L. and Foil L. (2009). Development of a mathematical model for transmission of trypanosomes and other pathogens of cattle transmitted by tabanids. International Journal of Parasitology. 33: 333-346. doi:10.1016/j.ijpara.2008.07.004.

Desquesnes, M. Holzmuller, P., Lia, D., Dargantes, A., Lun, Z. and Jittaplapong, S. (2013). Trypanosoma evansi and Surra: A review and perspective on origins, 
history, distribution, taxonomy, morphology, host and pathogenic effects. BioMed Research International. 39: 333-346. http://dx.doi.org/10.1155/2013/194176.

Diallo, P. B., Truc, P. and Laveissiére, C. (1997). A new method for identifying blood meals of human origin in tsetse flies. Acta Tropica. 63:61-64. doi:10.1016/S0001706X(97)86626-0.

Esterhuizen, J. (2006). Seasonal abundance of horse flies (Diptera: Tabanidae) from two conservation areas in north eastern KwaZulu-Natal Province, South Africa. African Entomology. 14(2): 395-397.

Foil, L., D. and Gorham, R. (2000). Mechanical Transmission of Disease Agents by Arthropods. In Medical Entomology: A textbook on public health and veterinary problems caused by arthropods (ed. Eldrige, B. F. and Edman, J.), pp. 461-514. Kluwer Academic Publishers. California, USA.

Gillingwater, K., Mamabolo, M. V. and Majiwa P. A. O. (2010). Prevalence of mixed Trypanosoma congolense infections in livestock and tsetse in KwaZulu-Natal, South Africa. Journal of the South African Veterinary Association. 81(4): 219-223.

Gutierrez, C., Desquesnes, M., Touratier, L. and Büscher, P. (2010). Trypanosoma evansi: Recent outbreaks in Europe. Veterinary Parasitology. 174: 26-29. doi:10.1016/j.vetpar.2010.08.012.

Hall, T. A. (1999). BioEdit: a user-friendly biological sequence alignment editor and analysis program for Windows 95/98/NT. Nucleic Acids Symposium Series. 41:95-98.

Hornok, S., Fedák, A., Baska, F., Hofmann-Lehmann. R. and Basso, W. (2014). Bovine besnoitiosis emerging in Central-Eastern Europe, Hungary. Parasites and Vectors. 7: 20. doi:10.1186/1756-3305-7-20. 
Hornok, S., Fedák, A., Baska, F., Basso, W., Dencső, L., Tóth, G., Szeredi, L., Abonyi, T. and Dénes, B. (2015). Vector-borne transmission of Besnoitia besnoiti by blood-sucking and secretophagous flies: epidemiological and clinicopathological implications. Parasites and Vectors. 8: 450. DOI 10.1186/s13071-015-1058-0.

Hunfeld, K. P., Hildebrandt, A. and Gray, J. S. (2008). Babesiosis: Recent insights into an ancient disease. International Journal for Parasitology. 38: 1219-1237. doi:10.1016/j.ijpara.2008.03.001.

Ica, A., Vatansever, Z., Yildirim, A., Duzlu, O. and Inci, A. (2007). Detection of Theileria and Babesia species in ticks collected from cattle. Veterinary Parasitology. 148: 156-160. doi:10.1016/j.vetpar.2007.06.003.

Itina, V. I., Noutcha, A. M. E. and Okiwelu, S. N. (2013). Spatial and Temporal Distribution of Tabanids (Diptera: Tabanidae) in Akwa Ibom State, Nigeria. Research in Zoology. 3(2): 62-65. doi: 10.5923/j.zoology.20130302.03.

Katoh, K. and Standley, D. M. (2013). MAFFT Multiple Sequence Alignment Software Version 7: Improvements in Performance and Usability. Molecular Biology and Evolution. 30(4): 772-780. doi:10.1093/molbev/mst010.

Krinsky, W. L. and Pechuman, L. L. (1975). Trypanosomes in horse flies and deer flies in central New York State. Journal of Parasitology. 61(1): 12-16.

Laohasinnarong, D., Goto, Y., Asada, M., Nakao, R., Hayashida, K., Kajino, K., Kawazu, S., Sugimoto, C., Inoue, N. and Namangala, B. (2015). Studies of trypanosomiasis in the Luangwa valley, north-eastern Zambia. Parasites and Vectors. 8:497. doi 10.1186/s13071-015-1112-y.

Lessard, D. B. and Yeates, D.K. (2012). Anzomyia (Diptera: Tabanidae: Pangoniinae: Scionini): a new genus of Australian and New Zealand horse fly, 
including the description of three new species. Insect Systematics and Evolution. 43: 101-116. doi:10.1163/187631212X637526.

Lessard, B. D., Cameron, S. L., Bayless, K. M., Wiegmann, B. M. and Yeates, D. K. (2013). The evolution and biogeography of the austral horse fly tribe Scionini (Diptera: Tabanidae: Pangoniinae) inferred from multiple mitochondrial and nuclear genes. Molecular Phylogenetics and Evolution. 68(3): 516-540. http://dx.doi.org/10.1016/j.ympev.2013.04.030.

Mamabolo, M. V., Ntantiso, L., Latif, A. and Majiwa, P. A. O. (2009). Natural infection of cattle and tsetse flies in South Africa with two genotypic groups of $\begin{array}{llll}\text { Trypanosoma congolense. } & \text { Parasitology. 136: }\end{array}$ doi:10.1017/S0031182009005587.

Masiga, D. K., Smyth, A. J., Hayes, P, Bromidge, T. J. and Gibson, W. C. (1992). Sensitive detection of trypanosomes in tsetse flies by DNA amplification. International Journal of Parasitology. 22: 909-918.

Mbewe, N.J., Namangala, B., Sitali, L., Vorster, I. and Michelo, C. (2015). Prevalence of pathogenic trypanosomes in anaemic cattle from trypanosomosis challenged areas of Itezhi-tezhi district in central Zambia. Parasites and Vectors. 8: 638. doi:10.1186/s13071-015-1260-0.

Morita, S. (2008). A revision of the Philoliche aethiopica species complex (Diptera: Tabanidae). African Invertebrates. 49 (1): 129-158.

Morita, S. I., Bayless, K. M., Yeates, D. K. and Wiegmann, B. M. (2016). Molecular phylogeny of the horse flies: a framework for renewing tabanid taxonomy. Systematic Entomology. 41: 56-72. doi:10.1111/syen.12145. 
Motloang, M. Y., Masumu, J., Mans, B. J. and Latif, A. (2014). Virulence of Trypanosoma congolense strains isolated from cattle and African buffaloes (Syncerus caffer) in KwaZulu-Natal, South Africa. Onderstepoort Journal of Veterinary Research. 81(1): 679-685. doi:10.4102/ojvr.v81i1.679.

Mtshali, P. S., Tsotetsi, A. M., Thekisoe, M. M. O, and Mtshali, M. S. (2014). Nested PCR detection and phylogenetic analysis of Babesia bovis and Babesia bigemina in cattle from peri-urban localities in Gauteng province, South Africa. The Journal of Veterinary Medical Science. 76(1): 145-150. doi:10.1292/jvms.13-0197; J. Vet. Med. Sci. 76(1): 145-150, 2014.

Mwandiringana, E., Gori, E., Nyengerai, T. and Chidzwondo, F. (2012). Polymerase chain reaction (PCR) detection of mixed trypanosome infection and blood meal origin in field-captured tsetse flies from Zambia. African Journal of Biotechnology. 11(79): 14490-14497. doi:10.5897/AJB12.2134.

Namazi, F., Oryan, A. and Sharifiyazdi, H. (2010). Genetic characterization of the causative agent of besnoitiosis in goats in Iran on the basis of internal transcribed spacer rDNA and its comparison with Besnoitia species of other hosts. Parasitology Research. 108: 633-638. doi:10.1007/s00436-010-2107-4.

Nevill, E. M., Stuckenberg, B. R. and Phelps, R. J. (1994). Vectors: Tabanidae. In Infectious Diseases of Livestock: With Special Reference to Southern Africa. (ed. Thomson, G. R. and Tustin, R. C.), pp. 62-67. Oxford University Press, Incorporated, UK.

Nguyen, T., Motsiri, S. M., Taioe, M. O., Mtshali, S. M., Goto, Y., Kawazu, S., Thekisoe, O. M. M. and Inoue, N. (2015). Application of crude and recombinant ELISAs and immunochromatographic test for serodiagnosis of animal trypanosomosis in the Umkhanyakude district of KwaZulu-Natal province, South Africa. Journal of Veterinary Medical Science. 77(2):217-220. doi:10.1292/jvms.14-0330. 
Njiru, Z. K., Constantine, C. C., Guya, S., Crowther, J., Kiragu, J. M., Thompson, R. C. A. and Da' Vila, A. M. R. (2005). The use of ITS1 rDNA PCR in detecting pathogenic African trypanosomes. Parasitology Research. 95: 186-192. doi:10.1007/s00436-004-1267-5.

Office International des Épizooties. (2008). Theileriosis: OIE Terrestrial Manual. World Organisation for Animal Health. Paris, France.

Okiwelu, S. N. (1975). Tabanidae of a "Miombo" woodland in the Republic of Zambia. Mosquito News. 35(3): 399-401.

Okiwelu, S. N. (1976). Distribution of Tabanidae at the Chakwenga Game Reserve, Republic of Zambia. Mosquito News. 36(3):277-279.

Oldroyd, H. (1954). The horse-flies (Diptera: Tabanidae) of the Ethiopian Region: II: Tabanus and related genera. London British Museum (Natural History). x. London, UK.

Pienaar, R., Potgieter, F. T., Latif, A., Thekisoe O. M. and Mans, B. J. (2011). The Hybrid II assay: a sensitive and specific real-time hybridization assay for the diagnosis of Theileria parva infection in Cape buffalo (Syncerus caffer) and cattle. Parasitology. doi:10.1017/S0031182011001454.

Renda, S., De Beer, C. J., Venter, G. J. and Thekisoe, O. M. M. (2016). Evaluation of larviposition site selection of Glossina brevipalpis. Veterinary Parasitology. 215: 9295. http://dx.doi.org/10.1016/j.vetpar.2015.11.012.

Sahinduran, S. (2012). Protozoan Diseases in Farm Ruminants. In A Bird's-Eye View of Veterinary Medicine. (ed. Perez-Marin, C. C.), pp 473-497. InTech Publishers, Rijeka, Croatia. 
Sari, A., Duran, M. and Bardakci, F. (2012). Discrimination of Orthocladiinae species (Diptera: Chironomidae) by using cytochrome c oxidase subunit I. Acta Zoologica Bulgarica. 4: 73-80.

Service, M. (2012). Horse flies (Tabanidae). Medical Entomology for Students, 5th Edn. Cambridge University Press. Cambridge, UK.

Simuunza, M., Weir, W., Courcier, E., Tait, A. and Shiels, B. (2011). Epidemiological analysis of tick-borne diseases in Zambia. Veterinary Parasitology. 175: 331-342. doi:10.1016/j.vetpar.2010.09.027.

Sinshaw, A., Abeb, G., Desquesnes, M. and Yoni, W. (2006). Biting flies and Trypanosoma vivax infection in three highland districts bordering lake Tana, Ethiopia. Veterinary Parasitology. 142: 35-46. doi:10.1016/j.vetpar.2006.06.032.

Sumba, A. L., Mihok, S. and Oyieke, F. A. (1998). Mechanical transmission of Trypanosoma evansi and T. congolense by Stomoxys niger and $S$. taeniatus in a laboratory mouse model. Medical and Veterinary Entomology. 12: 417-422. doi:10.1046/j.1365-2915.1998.00131.x.

Terkawia, M. A., Thekisoe, O. M. M., Katsande, C., Latif , A. A., Mans, B. J., Matthee, O., Mkize N., Mabogoane, N., Marais, F., Yokoyama, N., Xuana, X. and Igarashia, I. (2011). Serological survey of Babesia bovis and Babesia bigemina in cattle in South Africa. Veterinary Parasitology. 182: 337-342. doi:10.1016/j.vetpar.2011.05.047.

Thompson, B. E., Latif, A. A., Oosthuizen, M. C., Troskie, M. and Penzhorn, B. L. (2008). Occurrence of Theileria parva infection in cattle on a farm in the Ladysmith district, KwaZulu-Natal, South Africa. Journal of the South African Veterinary Association. 79: 31-35. 
Usher, J. (1972). A review of the South African horse fly fauna (Diptera: Tabanidae). Ann. Natal. Museum. 21(2): 459-507.

Veer, V. (1999). Notes on Tabanidae (Diptera) that are Surra vectors or pestiferous with description of a new species of Tabanus from India. Oriental Insects. 33(1): 247266. doi:10.1080/00305316.1999.10433793.

Van den Bossche, P. (2001). Some general aspects of the distribution and epidemiology of bovine trypanosomosis in southern Africa. International Journal of Parasitology. 31: 592-598.

Yamada, S., Konnai, S., Imamura, S., Simuunza, M., Chembensofu, M., Chota, A., Nambota, A., Onuma, M. and Ohashi, K. (2009). PCR-based detection of blood parasites in cattle and adult Rhipicephalus appendiculatus ticks. The Veterinary Journal. 182: 352-355. doi:10.1016/j.tvjl.2008.06.007.

Yagi, A. I. (1968). A contribution to the knowledge of the Tabanidae of the Sudan. PhD thesis. University of Khartoum. Sudan.

Yeates, D. K., Wiegmann, B. M., Courtney, G. W., Meier, R., Lambkin, C. and Pape, T. (2007). Phylogeny and systematics of Diptera: Two decades of progress and prospects. Zootaxa 1668: 565-590.

Yusufmia, S. B. A. S., Collins, N. E., Nkuna, R., Troskie, M., Van den Bossche, P. and Penzhorn, B. L. (2010). Occurrence of Theileria parva and other haemoprotozoa in cattle at the edge of Hluhluwe-iMfolozi Park, KwaZulu-Natal, South Africa. Journal of the South African Veterinary Association. 81(1): 45-49. 0038-2809 JI S.Afr.vet.Ass. (2010) 81(1): 45-49.

Zumpt, F. (1949). Medical and veterinary importance of horse flies. South African Medical Journal. Johannesburg, South Africa. 


\section{Figure Captions}

Fig. 1. A is the map of southern Africa. $B$ is the map of Zambia highlighting the sampled provinces namely Eastern Province with the Green Star and Central Province with the Red Star. C is the map of South Africa highlighting the sampled province and the Blue star shows where in KwaZulu-Natal Province samples were collected. The maps were created using the ArcGIS online software (https://arcgis.com) with modifications.

Fig. 2. Images of tabanids flies identified in this study, [1] head, abdomen ([2] dorsal and [3] ventral and [4] a single wing). A-Ancala africana; B-Atylotus agrestis; CAtylotus diurnus; D - Atylotus fuscipes; E - Atylotus nigromaculatus; F - Philoliche aethiopica; G - Tabanus gratus; H - Tabanus taeniatus; I - Tabanus laverani; J Tabanus par; K - Tabanus taeniola; L - Haematopota sp.; M - Tabanus conformis; N Tabanus conspicuus.

Fig. 3a. Phylogenetic analysis by Maximum Likelihood (ML) method using MEGA 6 (Tamura et al., 2013) showing the position of South African and Zambian tabanid flies. The tree shows 7 major clades (I - VII), namely, Clade I - Tabanus 1 spp.; Clade II Hybomitra spp.; Clade III - Tabanus 2 spp.; Clade IV - Haematopota spp.; Clade V Atylotus spp.; Clade VI - Chrysops spp. and Clade VII - Philoliche spp.

Fig. 3b. Phylogenetic analysis by Bayesian inference (BI) constructed using MrBayes. Distinct clades are represented in different colours whereby Tabanus spp. 1 is represented by brown, Hybomitra spp. by green, Tabanus spp. 2 represented by purple, Atylotus spp. by orange, Chrysops by pink, Haematopota spp. by blue and members of Philoliche spp. by red colour respectively. 
S. 1. Alignment of $18 S$ rRNA gene showing identity of Trypanosoma brucei-like species obtained in this study with T. brucei [Suzena - AF306775]; T. evansi [Isolate 006 - HQ593640] and T. evansi [Strain B2 - FJ712715].

S. 2. Alignment of $18 S$ rRNA gene showing identity of Babesia bigemina from the current study with Babesia bigemina [strain MT26 - KU206297] and [strain MT25 KU206296].

S. 3. Alignment of $18 \mathrm{~S}$ rRNA gene sequence showing the identity of Theileria parva obtained in this study with Theileria parva [HQ684067] and [KM211712].

S. 4. Alignment of two $18 S$ rRNA gene sequences from Trypanosoma evansi-like species obtained from Zambian tabanid flies with Trypanosoma evansi [isolate HQ593640] and [buffalo strain - FJ7127151]

S.5. PCR using TCS primers for the detection of T. congolense Savannah from tabanid flies collected from South Africa. M is a molecular marker, -ve is the negative control, +ve is the T. congolense IL 3000 positive control. L1 to L11 are samples that tested positive for $T$. congolense Savannah.

S. 6. PCR using TBR primers for the detection of Trypanozoon species collected from South Africa and Zambia. $M$ is a molecular marker, -ve is no template control, +ve is T. b. brucei (GUTat 3.1) positive control. L1 is a positive sample from South Africa and L2 to L7 are positive samples from Zambia. 
Table 1. Primers used in the current study

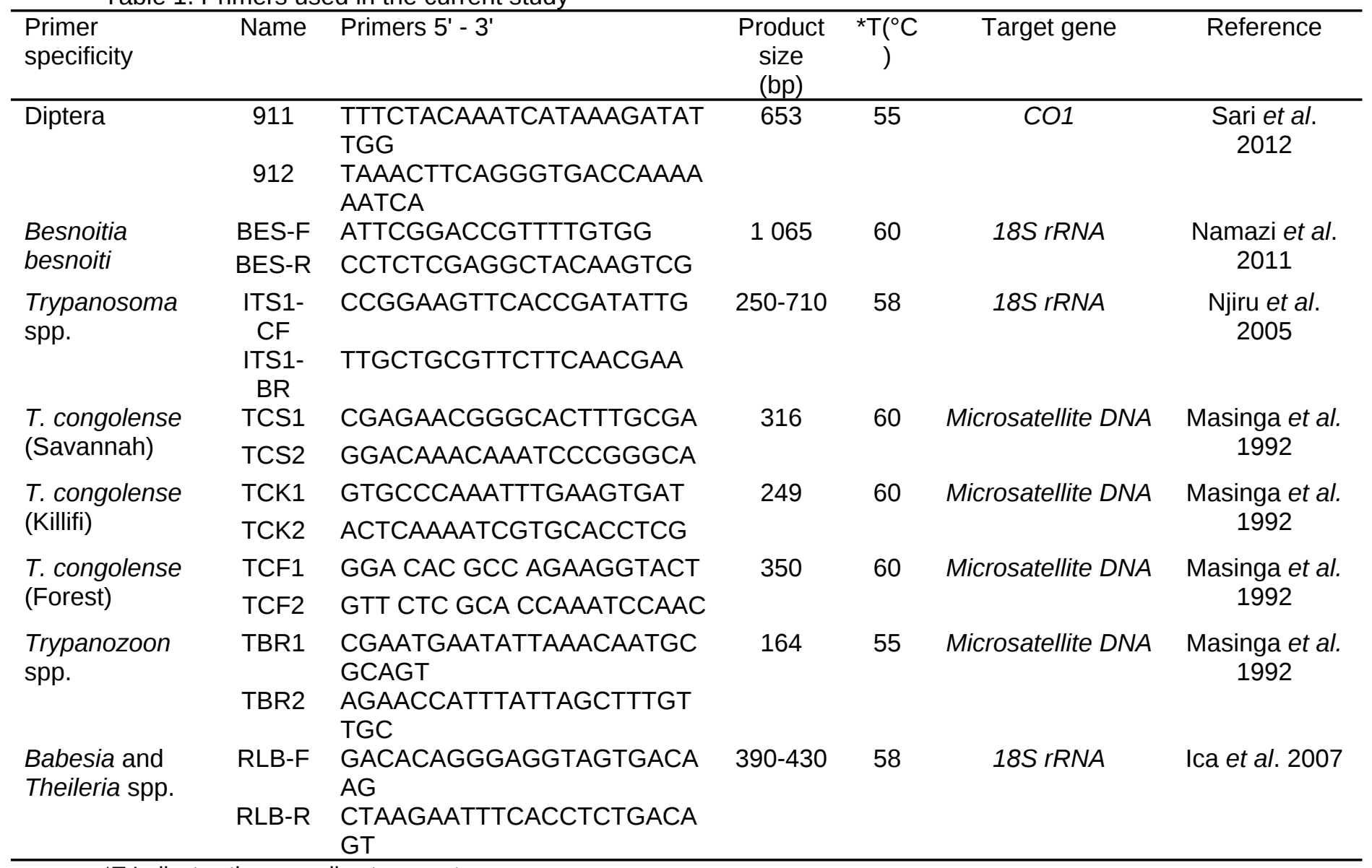

${ }^{\star} \mathrm{T}$ Indicates the annealing temperature 


\begin{tabular}{|c|c|c|c|c|}
\hline \multirow[b]{2}{*}{ Tabanid fly species } & \multicolumn{3}{|c|}{ Game Reserve sampled } & \multirow[b]{2}{*}{$\begin{array}{c}\text { Total number of fly } \\
\text { samples }\end{array}$} \\
\hline & $\begin{array}{l}\text { Hluhluwe- } \\
\text { Imfolozi (\%)* }\end{array}$ & $\begin{array}{c}\text { Charters } \\
\text { Creek }(\%)^{\star}\end{array}$ & $\begin{array}{c}\text { Phinda Private } \\
(\%)^{\star}\end{array}$ & \\
\hline 1. Ancala africana & $5(38.5)$ & $7(53.8)$ & $1(7.7)$ & 13 \\
\hline 2. Atylotus agrestis & $7(63.6)$ & $4(36.4)$ & $0(0)$ & 11 \\
\hline 3. Atylotus fuscipes & $6(60.0)$ & $4(40.0)$ & $0(0)$ & 10 \\
\hline $\begin{array}{l}\text { 4. Atylotus } \\
\text { nigromaculatus }\end{array}$ & $5(41.7)$ & $4(33.3)$ & $3(25.0)$ & 12 \\
\hline 5. Philoliche aethiopica & $2(33.3)$ & $4(66.7)$ & $0(0)$ & 6 \\
\hline 6. Tabanus gratus & $3(100)$ & $0(0)$ & $0(0)$ & 3 \\
\hline 7. Tabanus taeniatus & $4(28.6)$ & $10(71.4)$ & $0(0)$ & 14 \\
\hline 8. Tabanus laverani & $4(80.0)$ & $1(20.0)$ & $0(0)$ & 5 \\
\hline 9. Tabunus par & $43(27.9)$ & $87(56.5)$ & $24(15.6)$ & 154 \\
\hline 10. Tabanus taeniola & $30(21.1)$ & $85(59.9)$ & $27(19.0)$ & 142 \\
\hline Total & $109(29.46)$ & $206(55.68)$ & $55(14.86)$ & 370 \\
\hline
\end{tabular}

*Indicates the abundance of the tabanid flies found per sampled game reserves from South Africa in percentages 


\begin{tabular}{|c|c|c|c|c|}
\hline & Species & Central Province $(\%)^{*}$ & Northern Province $(\%)^{\star}$ & samples \\
\hline 1. & Atylotus agrestis & $1(6.25)$ & $15(93.75)$ & 16 \\
\hline 2. & Atylotus diurnus & $1(14.3)$ & $6(85.7)$ & 7 \\
\hline 3. & Haematopota sp. & $0(0)$ & $3(100)$ & 3 \\
\hline \multirow[t]{2}{*}{4.} & Tabanus & & & \\
\hline & taeniatus & $0(0)$ & $77(100)$ & 77 \\
\hline 5. & Tabanus taeniola & $3(7.3)$ & $38(92.7)$ & 41 \\
\hline 6. & Tabanus par & $1(12.5)$ & 7 (87.5) & 8 \\
\hline \multirow[t]{2}{*}{7.} & Tabanus & & & \\
\hline & conspicuus & $1(100)$ & $0(0)$ & 1 \\
\hline \multirow[t]{3}{*}{8.} & Tabanus & & & \\
\hline & conformis & $0(0)$ & $4(4)$ & 4 \\
\hline & Total & $7(4.46)$ & $150(95.54)$ & 157 \\
\hline
\end{tabular}

*Indicates the abundance of the tabanid flies found per sampled game reserves from Zambia in percentages 
Table 4. Prevalence of protozoan parasites detected from tabanid flies collected from South Africa and Zambia

\begin{tabular}{|c|c|c|c|c|c|c|c|c|c|}
\hline Country & Species & $\begin{array}{l}\text { Babesia bigemina } \\
(\%)^{\star}\end{array}$ & $\begin{array}{l}\text { Besnoitia } \\
\text { besnoiti }(\%)^{\star}\end{array}$ & $\begin{array}{l}\text { Theileria } \\
\text { parva (\%)* }\end{array}$ & $\begin{array}{l}\text { Trypanosoma } \\
\text { brucei }(\%)^{\star}\end{array}$ & $\begin{array}{l}\text { Trypanosoma } \\
\text { congolense S } \\
(\%)^{*}\end{array}$ & $\begin{array}{l}\text { Trypanosoma } \\
\text { evansi }(\%)^{\star}\end{array}$ & $\begin{array}{l}\text { Trypanosoma } \\
\text { theileri }(\%)^{\star}\end{array}$ & $\begin{array}{l}\text { Total number of } \\
\text { flies }(N)^{\star}\end{array}$ \\
\hline \multirow{10}{*}{$\begin{array}{l}\text { South } \\
\text { Africa }\end{array}$} & Ancala africana & $0(0)$ & $0(0)$ & $0(0)$ & $0(0)$ & $0(0)$ & $0(0)$ & $0(0)$ & 13 \\
\hline & Atylotus agrestis & $0(0)$ & $0(0)$ & $0(0)$ & $0(0)$ & $0(0)$ & $0(0)$ & $0(0)$ & 11 \\
\hline & Atylotus fuscipes & $0(0)$ & $0(0)$ & $0(0)$ & $0(0)$ & $0(0)$ & $0(0)$ & $0(0)$ & 10 \\
\hline & $\begin{array}{l}\text { Atylotus } \\
\text { nigromaculatus }\end{array}$ & $0(0)$ & $0(0)$ & $0(0)$ & $0(0)$ & $0(0)$ & $0(0)$ & $0(0)$ & 12 \\
\hline & $\begin{array}{l}\text { Philoliche } \\
\text { aethiopica }\end{array}$ & $0(0)$ & $0(0)$ & $0(0)$ & $0(0)$ & $0(0)$ & $0(0)$ & $0(0)$ & 6 \\
\hline & Tabanus gratus & $0(0)$ & $0(0)$ & $0(0)$ & $0(0)$ & $0(0)$ & $0(0)$ & $0(0)$ & 3 \\
\hline & Tabanus laverani & $0(0)$ & $0(0)$ & $0(0)$ & $0(0)$ & $0(0)$ & $0(0)$ & $0(0)$ & 5 \\
\hline & Tabanus taeniatus & $0(0)$ & $0(0)$ & $0(0)$ & $0(0)$ & $0(0)$ & $0(0)$ & $0(0)$ & 14 \\
\hline & Tabanus taeniola & $0(0)$ & $0(0)$ & $0(0)$ & $0(0)$ & $10(7.42)$ & $0(0)$ & $7(4.93)$ & 142 \\
\hline & Tabunus par & $0(0)$ & $0(0)$ & $0(0)$ & $1(0.65)$ & $6(3.90)$ & $0(0)$ & $8(5.19)$ & 154 \\
\hline Subtotal & & $0(0)$ & $0(0)$ & $0(0)$ & $1(0.27)$ & $16(4.32)$ & $0(0)$ & $15(4.05)$ & 370 \\
\hline \multirow[t]{8}{*}{ Zambia } & Atylotus agrestis & $10(62.50)$ & $0(0)$ & $0(0)$ & $0(0)$ & $0(0)$ & $0(0)$ & $0(0)$ & 16 \\
\hline & Atylotus diurnus & $7(100.0)$ & $0(0)$ & $0(0)$ & $0(0)$ & $0(0)$ & $0(0)$ & $0(0)$ & 7 \\
\hline & Haematopota sp. & $0(0)$ & $0(0)$ & $0(0)$ & $0(0)$ & $0(0)$ & $0(0)$ & $0(0)$ & 3 \\
\hline & Tabanus taeniatus & $3(3.90)$ & $0(0)$ & $0(0)$ & $0(0)$ & $0(0)$ & $0(0)$ & $0(0)$ & 77 \\
\hline & Tabanus taeniola & $7(17.07)$ & $0(0)$ & $5(12.20)$ & $0(0)$ & $0(0)$ & $7(17.07)^{\star \star}$ & $0(0)$ & 41 \\
\hline & Tabanus par & $6(75.0)$ & $0(0)$ & $0(0)$ & $0(0)$ & $0(0)$ & $7(87.50)^{\star \star}$ & $0(0)$ & 8 \\
\hline & $\begin{array}{l}\text { Tabanus } \\
\text { conspicuus }\end{array}$ & $1(100.0)$ & $0(0)$ & $0(0)$ & $0(0)$ & $0(0)$ & $0(0)$ & $0(0)$ & 1 \\
\hline & Tabanus conformis & $0(0)$ & $2(50.0)$ & $0(0)$ & $0(0)$ & $0(0)$ & $0(0)$ & $0(0)$ & 4 \\
\hline $\begin{array}{l}\text { Subtotal } \\
\text { Total }\end{array}$ & & $34(23.57)$ & $2(1.27)$ & $5(3.18)$ & $0(0)$ & $0(0)$ & $14(8.92)$ & $0(0)$ & $\begin{array}{l}157 \\
527\end{array}$ \\
\hline
\end{tabular}

* Indicates the average prevalence of the tested pathogens from the positively tested tabanid flies

**Indicates the significance for the prevalence of the detected pathogens at $p<0.05$ calculated using Fisher's Exact Test by comparing the positively tested flies per pathogen detected 